\title{
When interactions are interruptions: An ethnographic study of information-sharing by speech and language therapists and nurses on stroke units
}

*Dr Rachel Barnard: https://orcid.org/0000-0003-4319-9550

*Dr Madeline Cruice: https://orcid.org/0000-0001-7344-2262

Dr Julia Jones: https://orcid.org/0000-0003-3221-7362

*Division of Language and Communication Science, School of Health Sciences, City, University of London, London, UK

*Centre for Research in Public Health and Community Care (CRIPACC), University of Hertfordshire, Hatfield, UK

Purpose: To explore how the information-sharing context influences how speech and language therapy (SLT) and nursing staff interact on stroke units and what they discuss.

Methods: Ethnographic methodology was used, with data collected during 40 weeks of fieldwork across three inner city stroke units in the UK. Data comprised field notes collected during 357 hours of participant observation and 43 interviews. Interviews were conducted with 14 SLTs, 1 SLT assistant, 24 registered nurses and 4 nursing assistants.

Results: This paper is focused on informal information-sharing. SLTs and nurses had different experiences of time and space (the temporal-spatial context) with respect to ward presence and proximity to patients, influencing how they interacted, the content of their talk and their relationships. Most interactions had the quality of interruptions, in which SLTs seized moments in between nursing tasks. Conditions were less suited to sharing information about communication than swallowing and SLTs felt more allied to other therapists than nurses.

Conclusion: The temporal-spatial context impeded information-sharing, particularly about patients' communication needs. Consideration should be given to developing relationships between SLTs and nurses as key partners for patient care and raising the profile of communication information in ways that are relevant and useful to nursing work.

Keywords: Speech and language therapist; nurse; stroke; interruptions; ethnography; communication 


\section{Background}

Patients admitted to hospital with stroke who receive care organised by stroke specialist clinicians have been found to have better outcomes with respect to mortality and dependency than patients whose care is not organised in this way [1]. However, UK guidance for how different stroke professionals should enact 'organised care' through information-sharing focuses almost entirely on structured routes such as weekly meetings of a 'co-ordinated multidisciplinary team' [2:17]. This does not reflect the unplanned exchanges that take place in corridors, nursing stations and other spaces that are commonly used for informal discussion about patients [3,4]. Meetings are important spaces for team decision-making [5], acting as a very visible representation of the team at work $[3,6]$. However, much of the day-to-day planning of patient care appears to occur through informal exchanges between professionals piecing together different sources of knowledge $[3,7,8]$. It has been frequently reported that meetings are limited in their effectiveness as information-sharing spaces, particularly for nurses $[8,9]$. Patient demands can make it hard for nurses to leave the ward to attend meetings [5,10]. Nurses who do attend are disadvantaged because they often represent patients that they have little personal knowledge of [11], and they can experience their contributions as under-valued by therapists [12]. Such limitations reinforce the importance of informal routes for information exchange. However informal exchanges are essentially opportunistic [3], usually requiring one party to temporarily stop what they are doing to attend to interaction with another member of the healthcare team [13-15]. Understanding more about how professionals attempt to accomplish their goals in this context has potential to inform coordinated patient care [3].

The focus of this study is information-sharing on acute stroke units between two professional groups; speech and language therapy (SLT) and nursing staff (herein referred to as SLTs or nurses unless SLT or nursing assistants are being specifically referenced). Meeting the 
communication and swallowing needs of patients involves overlap between SLTs' specialist knowledge and nurses' knowledge in the context of caring holistically for the patient. Recognition for the importance of assessing and managing the communication and swallowing disorders (dysphagia) that are commonly associated with stroke is reflected in stroke guidelines internationally $[2,16]$. During the first 72 hours of stroke onset communication disorders have a reported prevalence of $64 \%$ [17]. The incidence of swallowing difficulties is variably reported between 40 and 78\% [18]. Communication difficulties make it hard for patients to indicate physical needs, make sense of medical procedures and processes, participate in decisions about their care, demonstrate their individual histories and have emotional needs for connectivity met [19]. Swallowing difficulties are associated with risks relating to airway patency, aspiration, inadequate nutrition and hydration [20] and taking medications orally [21], in addition to risks to health and wellbeing associated with curtailment and modification of food and drink [22]. SLTs are only present on wards intermittently and thus depend on nurses, both for the knowledge they derive through continuous care and to put any recommendations they make into practice [8].

Nurses who are providing direct care to patients are particularly challenged in their capacity to divert their attention from patient care towards incoming information from others due to their obligation to remain responsive to patients [23]. Studies in which interruptions have been observed in practice mostly focus on nurse to nurse interruptions. They provide evidence that disruption to nurses' focus can be detrimental to patient safety, but caution against understanding this at a surface level $[14,24]$. Intrusions to nursing work commonly occur during tasks such as medication-giving, documenting and providing direct care [15]. Incoming information can make it harder to focus on safe execution of the task at hand [15] but may nonetheless be needed to enhance holistic care $[14,24]$. Thus, interruptions can have positive 
as well as negative effects and willingness to divert attention towards the person interrupting is influenced by complex factors [14]. These include perceptions of necessity, personal disposition and relationships [7,13,14,24].

Observations of professionals in interaction on wards indicate that seemingly chance encounters may be less opportunistic than they appear [7]. The small amount of research exploring the mechanics of such encounters suggests that identifying and seeking out the right person is challenging [25] and achieving the desired exchange involves purposeful positioning and waiting [7]. The time available for information-sharing between SLTs and nurses is limited by therapists' reduced ward presence and constraints on nurses' capacity [8]. These also restrict opportunities for developing quality relationships [8]. Interaction can be associated with tension, particularly when specialist knowledge is perceived to hold advantaged status and when nurses' roles are not highly valued [26-28]. There is little known from existing research regarding how clinicians manage their need to share information in a context that requires them to interrupt the flow of work of another. Specifically, no previous research has been identified that explores how SLTs and nurses manage their information-sharing needs with respect to patients with stroke-associated communication and swallowing disorders.

The objectives of the study were: (1) to conduct fieldwork on three stroke units (hyper-acute and acute) to understand how information sharing happens within the usual work routines of SLTs and nurses, across different time periods and in different spaces on the units, and through verbal and written information sharing routes, and (2) to conduct interviews with SLT and nursing staff to understand perceptions of roles and interdependencies with respect to caring for patients with difficulties communicating and swallowing. This paper aims to generate new 
understanding for how the information-sharing context influences the nature of the information about patient management that passes between SLTs and nurses.

\section{Method}

The study adopted ethnographic methodology to explore information-sharing between SLTs and nurses, utilising three research methods including participant observation, interviews and document review of patient records. Ethnography has its origins in anthropological studies of remote cultures but is now used in a wide range of settings, including those such as healthcare that may be familiar to the researcher [29]. Ethnographic studies describe and interpret everyday ways of behaving that are often taken for granted by those who carry them out [30]. There is great variety amongst studies claiming an ethnographic approach, however, most definitions indicate that the pursuit of depth of knowledge, accomplished through spending long periods of time participating in other people's lives and collecting and analysing different types of data are central to the methodology [31]. Ethnography was selected for this study because immersive participation and the iterative use of multiple sources of data were anticipated to facilitate new understanding for how SLTs and nurses share information during their everyday work on stroke units. The focus on interaction between two disciplines extends previous research of therapist and nurse behaviour within interprofessional teams [3,4,26-28] through consideration of SLTs and nurses as a specific disciplinary dyad. The study was underpinned by the theoretical framework of symbolic interactionism and the belief that social life (and culture) is created through interaction [32].

The research was carried out on three wards located in two inner city NHS Trusts in the UK between September 2015 and July 2017. The three wards were selected on the basis of their capacity to illuminate team-based care across early acute and continuing inpatient stroke settings. Table 1 provides a summary of fieldwork periods. Wards were given fictitious names; 
Keats, Brooke and Shelley. Keats was a hyper-acute stroke unit admitting patients at the point of stroke onset for short admissions of less than a week. Brooke and Shelley provided continuing inpatient stroke care beyond the hyper-acute stage. Brooke was a dedicated stroke unit. Shelley comprised dedicated stroke bays embedded within two single sex neighbouring general neurology wards; a team of therapists and doctors worked exclusively with stroke patients across both wards. Nurses were based on just one ward and were variably allocated to bays of either stroke or general neurology patients. SLTs on Shelley and Brooke occupied neighbouring office space which they shared with other therapists. SLTs on Keats were permanently located on the ward.

Insert table 1: Fieldwork Summary.

\section{Ethical Procedures}

Ethical approval was granted by NRES Committee North West Preston (15/NW/0271) and sitespecific approvals were received from the Research and Development departments of the two NHS Trusts hosting the study. Prior to commencing fieldwork, information about the study was discussed with SLT and nurse leads and presented at interprofessional team meetings. At the start of each fieldwork period, the lead consultant introduced the study at interprofessional team meetings and posters were displayed on the ward and in office spaces. SLTs and nurses were given an information sheet explaining the study. Further verbal explanations were provided when inviting individuals to give written consent to participate. During fieldwork, the researcher repeatedly explained that SLTs and nurses were the focus of the study rather than the wider team. Patients were given a single page overview to inform them that a research study focused on information sharing between SLTs and nursing staff was taking place. Written consent was sought from patients to view SLT and nurse entries in the patient record. The SLT or nurse working with the patient made the first approach to the patient and was asked by the 
researcher if in their view the patient had capacity to consent. The researcher talked through the information sheet and drew additionally on her experience as a SLT to judge whether the patient was able to understand the information and provide informed consent. Patients were not involved further in the research once they had consented for their patient record to be reviewed. Patient data is not included in the current paper, which presents findings relating to informal SLT-nurse information-sharing only. Disciplinary differences in the time lapse between provision of information and recruitment into the study mirrored aspects of the empirical findings. Written consent from nursing participants was obtained both at the start and whilst the study was in progress due to shift working and frequent interruptions to the consent-seeking process. SLTs had more capacity to allocate time to hearing about the study and joined at the start.

\section{Participants}

Participants included SLTs (15), SLT Assistant (1), Registered Nurses (50), and Nursing Assistants (7). The SLT sample included the total population of SLTs allocated to, or covering absence, on the wards for the fieldwork period. All SLTs were observed; one left the Trust during fieldwork and was thus unable to be interviewed. Sampling was purposive for interviews with nursing staff to achieve diversity in gender and pay bands. Observed nursing staff represented a convenience sample. This was because it was important to recruit sufficient numbers of nursing staff so that informal interactions on the wards between a SLT and a nurse could be observed. One nurse and one nursing assistant declined to participate. Table 2 provides biographical information in composite across the three wards to reduce the potential for identification of research sites and individuals.

Insert Table 2: Participant Information. 
The most notable differences between SLT and nursing participants relate to gender and position on the pay scale. All the SLTs were female compared to $41(72 \%)$ of the nursing staff. Most nursing participants were employed at band 5, whereas most SLT participants were employed at band 6 or above.

\section{Data collection}

Data relating to informal interactions between SLTs and nurses included field notes of SLTnurse behaviour and interaction, and audio-recorded semi-structured interviews.

Fieldwork episodes: Ethnographic fieldwork periods occurred between 0715 and 2030, Monday to Sunday, with 357 hours logged in total. Fieldwork commonly commenced with nursing handover because starting the day with nurses helped build trust for developing field relationships. This was particularly important because the fieldworker (first author) is a SLT by profession. The majority of fieldwork episodes were 3-4 hours, with a range of 1-12 hours. Observed activities included structured routines such as meetings and nursing handover, and informal interactions. This paper presents findings relating to informal interactions only. All data was collected by the first author, who will be referred to in the first person as is conventional in ethnographic reporting [33].

Observation: Field notes were written by hand in a small notebook and later typed. Observations included general observation from places such as nursing stations, therapy offices and staff rooms, and periods of more directed observation of individual SLTs and nurses. Directed observations of SLTs involved staying quite close to individual SLTs as they moved around the ward. To avoid intruding on patient spaces, I waited outside bays in which SLTs were working. I aimed to capture interactions that occurred before or after SLT consultations with individual patients as well as other exchanges, such as when SLTs fetched food or drink from the kitchen to use for swallowing assessments. I also conducted directed observations of 
nurses to understand how they experienced interaction with SLT in the context of their wider roles with patients. Field notes were written openly when the clinical staff present were also writing and more discretely at other times. In order to create a detailed digital record of each fieldwork episode, notes were typed on return home, within the same day. This involved expanding on handwritten notes to report what had been observed in full sentences. Reflective comments were organised under three headings: emerging interpretations were recorded as 'themes and thoughts' and issues of importance to research processes were captured under 'methodological issues' and 'field relationships' [34].

Semi-structured interviews: 43 members of SLT and nursing staff were interviewed for their perspectives on their information-sharing practices, facilitating exploration of meaning through different lenses [35]. Semi-structured interviews were conducted with 14 SLTs, 1 SLT assistant, 24 nurses and 4 nursing assistants. Interviews were 21 to 55 minutes in length, with a mean of 48 minutes for SLTs and 36 minutes for nurses. This reflected reduced capacity of nursing staff to schedule time away from patient care. Five chose to be interviewed on their days off, whereas all SLTs were interviewed during the working day. Interviews were based around a topic guide to explore perceptions of clinical interests in common, roles and relationships, and issues surrounding training, as well as to extend insights from observations [29]. The interviews were audio-recorded, listened to in full and then personally transcribed to remain close to the data.

Reflexivity: A core feature of ethnographic work relates to attention to the role of the researcher in the inquiry through reflexivity [29]. Reflexivity refers to explicit self-questioning by the researcher across all aspects of the study [29]. It was particularly important to this study as a means of continuously reflecting on my position as a SLT exploring my own and another 
profession. I had previously worked as a SLT in team-based neurological rehabilitation in both Trusts, but not on the studied wards. However, whilst I shared clinical experience with the SLTs, there were times when shared life experiences brought me closer to the nurses. I was thus variably familiar and distant to the settings and members of the two disciplines over the duration of the study. The position I occupied can best be described as that of an acceptable marginal member [29]. I wore black trousers and a blue polo shirt in a conscious attempt to blend the clothing of the SLTs (trousers) and the nurses (top). My aim to appear somewhat 'staff like' but not signal belonging to either profession appeared successful with respect to SLTs and nurses. However, on explaining my presence to professionals outside of the study, I was sometimes attributed other roles, such as that of infection control nurse. I participated in social discourse and small acts of helping, such as answering the phone or fetching things, but essentially remained a friendly face at the edge of both SLT and nursing clinical worlds.

\section{Data analysis}

The aim of the analysis was to achieve interpretative 'thick' description of sufficient depth to meaningfully convey the information-sharing context of SLT and nursing work on stroke units [36]. The study developed iteratively as data were collected and analysed concurrently. The analytic approach followed Hammersley and Atkinson [29]. They support using principles from the constant comparative method to compare and contrast similarities and differences within and across data sources, and against emerging categories [37]. Because the aim in ethnography is often description or explanation rather than theory generation, their advice for coding is less structured than within grounded theory [29]. Analysis involved inter-related stages of familiarisation, coding using NVIVO 11 [38], and a paper-based search for patterns and contradictions. Field notes and interview transcripts were read repeatedly. All interview and observational data were initially open coded line by line and incident by incident as is appropriate for ethnographic data [39]. This was followed by more focused coding as data were 
organised into categories, which were continuously revised with the addition of new data through the iterative process [29]. The final stage on termination of fieldwork was manual inspection of the relationships between categories to develop a thematically organised explanation. This latter stage was a paper-based process in which patterns and relationships were creatively explored by mapping concepts and exploring new patterns and contradictions $[29,40]$.

Rigour: A number of criteria have been proposed for improving the trustworthiness of qualitative findings [41]. Of these, the most relevant to ethnography are credibility and transferability. Credibility relates to the believability of findings [41]. This was enhanced through prolonged engagement and triangulation of different sources of data. Specific processes included: actively searching for negative cases to determine whether they supported findings, demanded re-evaluation of findings, or were idiosyncratic outliers [35]; independent coding of a selection of field notes and interviews by the third author as a basis for discussion about emerging themes; ongoing discussion with supervisors with SLT and nurse education backgrounds; discussion of preliminary findings with participants on the researched wards, and keeping a reflexive diary as a means of challenging pre-conceptions. The analysis was informed by social constructionism thus these methods were used to further question rather than verify the data [42]. Social constructionist epistemology suggests that 'all knowledge, and therefore all meaningful reality as such, is contingent upon human practices, being constructed in and out of interaction between human beings and their world, and developed and transmitted within an essentially social context' [43:42]. Transferability is the potential for new knowledge to be transferred to other settings [41]. This was enhanced by including sufficient description to allow readers to judge the applicability of findings to their own circumstances [44] and by including multiple field sites [45]. 


\section{Findings}

The analysis led to an over-arching theme that the temporal-spatial context of interaction on stroke units impacted on how SLTs and nurses shared information. This context was found to create conditions through which information about swallowing was privileged over information about communication through informal and structured routes, and relationships between SLTs and nurses were hard to build [46]. This paper presents findings relating to informal information-sharing. First, a conceptual explanation of the temporal-spatial context is provided, followed by exploration of how SLT need to share information in brief 'windows in time' gave interaction an interruptive quality. The interactional factors that led SLTs to treat information about communication as a lesser priority when making use of these windows is then explored, followed by consideration of occasions when interactions had a less interruptive quality. Finally, constraints on development of SLT relationships with nurses is explored through consideration of SLTs' greater temporal-spatial alignment with other therapists.

In the following sections, extracts of observational data from field notes are identified as [FN + date recorded] and interview extracts by [pseudonym + (years of experience)]. Where interview extracts have been truncated for brevity this is indicated by (...). Extracts were selected on the basis of their capacity to clearly and concisely illustrate interpretations $[40,47]$. The aim was that they should represent triangulated data, be representative of multiple field observations, or the perspectives of more than one participant.

\section{Temporal-spatial context}

The work of SLTs and nurses was set within an environment in which they experienced time and space (the temporal-spatial context) in different ways (figure 1). The temporal dimension relates to differences in professional presence and caseload continuity. SLT presence was 'intermittent', reflecting usual practice of working 7.5 hours each day five days a week (with 
the exception of a rotating four-hour shift on Brooke on Saturdays, covered by one SLT and one SLT assistant). Whilst nursing presence was 'constant' across every 12.5-hour shift, covering day and night. It was usual for just one or two different SLTs ('few') to have continuous responsibility for a single patient for the duration of a patient's admission, with small numbers of additional SLTs from other wards providing occasional cover during SLT absence. In contrast, individual nurses transferred responsibility to new nurses at shift changes. Thus, several different nurses ('many') could potentially care for individual patients, and SLTs needed to interact with different nurses about the same patient over time. The key spatial difference related to the extent to which the two disciplines routinely worked in close proximity to patients. SLTs were more 'distal', coming and going from the bedside, whereas nurses allocated to patient bays remained 'proximal' to patients. The SLT temporal-spatial experience was closer to that of other therapists than nurses irrespective of geographical positioning. Therapists were stationed in neighbouring offices on Brooke and Shelley and permanently located on the ward on Keats. Relationally, therapists formed a discernible group on all wards. For example, one of the nursing stations on Keats was oriented to as therapists' space because therapists made it their own, using it as a base and discussing patients and completing administration there. Nurses reclaimed the space when therapists left for the day.

Insert figure 1.

\section{'Windows in time'}

SLT-nurse interactions usually served the purpose of sharing information which either discipline considered important for the immediate care needs of patients. Although SLTs and nurses were usually polite and friendly towards each other, interactions were time-restricted and perfunctory. They occurred in small 'windows in time' and temporarily disrupted nurses' 
flow of work. Nurses needed to remain responsive to the immediate needs of patients and they were almost always busy with a task or transitioning to another activity when SLTs sought them out. SLT decisions to wait in patient areas for nurses or patients to be free were found to be complex. Watchful waiting could result in patients requesting things of them. This often required them to seek out a nurse, creating interactional challenges that could be avoided by retreating to off-ward spaces.

SLTs spent a lot of time looking for nurses or waiting for them to step out from behind the curtains around a patient's bed. They encountered different nurses on different days and often found it difficult to match names to faces, particularly when they were new or infrequent visitors to the ward. Consequently, encounters often appeared more profession to profession than person to person. When the nurse allocated to a particular patient was not available, the SLT sometimes tried to find another nurse. However, this often involved being directed through a number of nurses, and potentially not finding anyone with knowledge of the patient. The SLT in the following fieldnote was covering absence of the usual SLT and keen to get back to her own wards. She had just completed an assessment and placed a sign with swallowing recommendations above the bed when the patient made a request of her that required her to seek out a nurse:

\section{$\underline{\text { Observation }}$}

She (SLT) puts the notice above the patient's bed and the patient asks her a question she can't answer about his cannula. She says she will pass on his query to a nurse. However, the nurse is behind the curtains, so she is unable to. She hangs about a bit but doesn't want to disturb the nurse and says: "he's going to hate me". I ask her why and 
she says she is aware that "the nurses get bothered all day by different people giving them little bits of information" [FN051015]

The SLT's words illustrate the commonly held view of SLT participants that nurses experienced their interactions with them as a disturbance. This created operational challenges for seizing on opportunities to talk when nurses were between tasks. SLTs were often seen hovering near a nurse engaged in activity, waiting for the nurse to look up. When nurses delayed giving their

attention it could appear as disregard for the approaching SLT. The following fieldnote indicates that this perceived lack of engagement may relate to nurse capacity. The SLT was behind the curtains with a patient and what she said to the patient was clearly audible from where the nurse was positioned at a mobile computer in the bay.

\section{Observation}

I can hear from behind the curtains that the SLT is recommending puree and thick (thickened fluids) and that the patient needs to take his time. When she is finished with the patient, she approaches the nurse, she stands in front of her and tries to read her name badge, but it is angled away. The nurse doesn't look up until she has been standing there for a few seconds. This is noticeable because as soon as the SLT steps out from behind the curtains the physiotherapist looks towards the SLT for an update and she tells her that he is safe to start eating [FN150916].

The nurse eventually looked up, and the SLT advised on safe consistencies for the patient, adding in a light-hearted manner "you probably heard me from behind the curtains". The nurse laughed and repeated what she had heard the SLT say to the patient: "slow down, slow down". 
This extract illustrates that what appeared as nurse inattention to the approaching SLT may have been a strategy to manage capacity; an attempt to complete the current task before taking on new information. The nurse's collegial response indicated that she was actually receptive to the interaction, despite taking longer than felt comfortable to look up. Exploration of similar episodes supported the indication that inability to alert a nurse by name made it harder for SLTs to soften the act of interrupting and gain attention. It was usually the case that there was no ideal time to have a conversation. The nurse in the following extract explains that when SLTs approach them to talk about patients, they are usually engaged in a series of activities, with no clear break for interaction to occur without disrupting the flow:

\section{$\underline{\text { Nurse Interview }}$}

They may come (...) and I'm busy with someone else, because we're always busy, we don't stop, we don't have the beginning and the end, there is always something to do continuously [Maryam (8yrs)]

SLTs based on other wards who provided absence cover had a particularly pressing need to convey information about swallowing. Although they were aware this required them to interrupt the flow of nursing work, they were compelled to close the episode of care, even if timing was not optimal.

\section{$\underline{\text { SLT Interview }}$}

I kind of want to get that done, tell them and then go (...) it does feel overloading (...) I know I forget little bits of information so I'm sure they would as well [Irene (13yrs)]. 
Several nurses reported that they considered SLTs to be respectful in the manner in which they approached them. They accepted interruptions as part of the job, particularly when the information was considered important for safe execution of patient care. However, they did not always have the capacity to hold information in that moment, either because they were in the middle of doing something else or they did not have the headspace. In one example, a SLT was seeking out the nurse in charge to discuss significant concerns raised by a patient about his care [FN100617]. At that moment the nurse in charge was deep in discussion with a bay nurse, so the SLT stood around tentatively for a while before approaching and politely asking if she had a minute to talk. The way the nurse responded ("my head is exploding") made it clear that she really didn't have the time or mental capacity for the conversation because the ward was short on nursing staff, however the discussion took place anyway.

\section{Perceptions of relevance influence how 'windows in time' are used}

Assessment and management of both swallowing and communication were core SLT roles. However, the small windows in time for interaction with nurses were mostly used to talk about swallowing. The information-sharing environment favoured fast exchanges of information that was accepted as relevant to patients' immediate healthcare needs. Swallowing information could be conveyed quite quickly and there was a shared sense of the importance of this information. SLTs routinely provided verbal updates following swallowing assessments and reviews and almost always reinforced them by placing signs detailing safe-swallowing advice above patients' beds. Nurses often sought out SLTs when they were concerned about patients' swallowing ability and jotted down verbal information from SLTs onto their handover sheets to use during the shift and pass on at shift changes. SLTs did provide information about communication to nurses but much less frequently and rarely with similar conviction to swallowing information. Detailed exploration of exceptions supported the infrequency of meaningful exchanges about communication. Those that did occur were associated with the 
SLT asking questions with a genuine spirit of inquiry, combined with the nurse giving full attention to the interaction. SLTs viewed information about swallowing as easier for nurses to make use of and less ambiguous.

\section{$\underline{\text { SLT Interview }}$}

I think swallowing stuff is much more practical, easy to follow, it's either you do this, you do that, you don't do this, you don't do that, and if you see this, then you come and get us basically, whereas communication is so much more subjective and doesn't always work (...) there's not like a rule book so much, whereas I think the swallowing, even though it is really like variable and there's a lot more going on, it does feel a bit more like a rule book [Yasmin (2yrs)]

SLTs perceived that nurses placed more value on information about swallowing than communication and this was borne out by nurses in interview who consistently equated the SLT role with swallowing. Nurses valued having their concerns listened to and wanted timely swallowing reviews with clear advice to enable them to execute tasks relating to the nutrition, hydration and medication needs of patients.

\section{$\underline{\text { Nurse Interview }}$}

We want them to ask us if we've got any concerns, and we want quite straightforward advice (...) even having specialised in stroke (...) I'm not concerned at all being taught how to like suck eggs or anything, I'm quite happy for someone to continually advise me the same stuff over and over again [Ava (2.5yrs)] 
The low profile of communication was a source of dissatisfaction reported by several SLTs during interview. They tended to self-limit the amount of communication information they shared. This was based on perceptions of nurses' limited time or interest, which were in turn based on previous interactions in which nurses were perceived to be more engaged with information about swallowing.

\section{$\underline{\text { SLT Interview }}$}

I find often it's less of a sort of a long dialogue, more of a "I appreciate you're really busy, you've got twenty thousand other things to do, so this is what you need to know from my assessment" (...). I try and think (...) what do they need to know from me, and that tends to be a bit briefer [Polly (5yrs)]

SLTs showed awareness that nurses had other priorities and little time to spare by keeping information relating to patients' communication very brief and purposeful. They delivered information at the same fast pace they used for conveying swallowing information. However, it was not well suited to this handling because it was more nuanced in nature and depended on a strong foundation of knowledge.

\section{$\underline{\text { SLT Interview }}$}

I didn't feel that what I was saying about the communication was necessarily being taken in, that the swallow was something like black and white, this is the texture, this is what they need, but when I was giving a bit of feedback about interacting with the patient and my suggestions, I felt like there wasn't that same attention being paid to that [Isabel (7yrs)] 
The following extract is typical of how communication information was offered and responded to. In this example the SLT used a fast pace of speech to convey two seemingly unrelated pieces of information about the patient's receptive abilities, one written, one verbal. The nurse acknowledges that communication information has been delivered, but with an emphasis on the patient's expressive ability. She swiftly moves onto concerns about medication-taking:

\section{$\underline{\text { Observation }}$}

SLT: He can actually read short sentences, so if, when you ask questions get him to nod Nurse: (nurse concurs that hard to understand his meaning) He was struggling a bit with his medications this morning

SLT: Was it crushed? (SLT suggests she try it with yoghurt). [FN070716]

It is difficult to see how this exchange could meaningfully be applied to supporting this patient's communication. It is very brief and there is no evidence of shared understanding that the SLT is providing information about receptive language. The SLT follows the nurse's topic change and offers information that is more tangible; how to give medication safely. Presenting information without expansion could thus leave its relevance to patient care unclear.

It was unusual for SLTs and nurses to seek each other out to discuss communication as they did for swallowing. SLTs were more likely to share information about communication if a nurse happened to be close by as consultations with patients began or ended. One of the nurses represented an exception. She herself identified as unusual amongst her nursing colleagues in her commitment to sharing information about the communication needs of patients. She tried out communication support strategies and shared these at nursing handover and with SLT, but she explained that other nurses mostly focused on 'nursing things', rather than communication. 
Nurses got by without much information about communication from SLTs, and SLTs felt nurses were quite good at working out for themselves how to communicate with patients. However, the costs to patients of limited exchange of information about communication is evident in the following extract:

\section{Nurse Interview}

I've got a patient that is going today, he has speech issues and swallowing issues, but we only know about the swallowing, I don't know anything about how to communicate to him properly, I know they've been talking to him, doing a lot of communication with him but I don't know how, the best way to communicate with him is, I just try and figure my own way (...) of doing it [William (6mths)]

In summary, SLTs and nurses appeared to accept a status quo whereby information about communication was not afforded high status in its relevance to patient care. Communication information was poorly aligned with a temporal-spatial context in which interaction was often disturbing to nursing work and favoured fast exchanges of easy-to-use information.

\section{When interactions had a less interruptive quality}

Search through the data for examples when interactions were less interruptive indicated that when SLTs and nurses were moving about the bay in the same time frame opportunities to talk about patient care arose more naturally. The effect of increased SLT ward presence was illustrated most clearly on Brooke, because the four-hour shift on Saturday provided a contrast to weekday practice. The Brooke SLTs could be quite distal to the wards on weekdays because they engaged in quite a lot of non-direct contact work relating to patients. They spent most of the Saturday shift on the ward. When asked to contrast Saturday working to weekday working, 
one SLT participant reflected that she had mentioned to one of the nurses her sense that Saturdays felt calmer and the nurse had replied in a jokey way that it was because "you lot (referring to therapists) aren't here". This reveals the impact on nurses of responding to the demands of other professionals as well as a relational division between nurses and therapists. SLTs experienced Saturdays as more conducive to relationships because nurses had fewer professionals vying for their time and there were no meetings. As a consequence, there was more potential for fuller sharing of information and social exchange.

Approaches from nurses to SLTs tended not to disturb the flow of SLT work in the same way as the reverse. One SLT related in interview an occasion when she had been asked by a nurse to review a patient's swallow three times in a day. This was offered as an example of a particularly satisfying exchange with a nurse. Although these requests represented unscheduled demands on her time, she found it satisfying because it showed that the nurse's goals for the patient were aligned with her own and she was pleased to be able to tailor treatment.

\section{$\underline{\text { SLT Interview }}$}

Obviously you haven't timetabled it in and you're busy you know, that's exactly what you want isn't it, you know if you've recommended something and it's not working you need to know so you can figure out what else to do and how to work around it [Rhea $(3 \mathrm{yrs})]$

When SLTs were interrupted, it appeared that information could be more easily accommodated with their priorities. This may be because information to SLTs from others was more likely to relate to their specialist roles, whereas information from SLTs to nurses needed to be accommodated within a wide gamut of roles relating to patient care and may not fit with current 
priorities. For example, over a half-hour period, one SLT was interrupted eleven times by various professionals, including nurses, whilst making entries in just two sets of patient notes. The SLT considered these discursive exchanges essential to managing her caseload and her only frustration was that they were not audited as patient contact [FN180915].

\section{The temporal-spatial context and development of relationships}

SLTs did not view their interactions with other therapists as interruptive. They viewed them as central to the rehabilitation and discharge agenda they had in common across the trajectory of the patient admission. They reported having frequent problem-solving conversations about the same patients with other therapists over consecutive days and weeks. In contrast the nurses they spoke to might not have a continuing relationship with the patient.

\section{$\underline{\text { SLT Interview }}$}

It's our role, our job to decide when patients are functionally safe to go home, so I think I allow myself more time to trouble shoot that with the therapists than with the nurses, because I appreciate that that's part of their (therapists') job as well [Amanda (5yrs)]

SLTs worked similar hours to other therapists and usually knew them by name. They had more capacity to talk away from the demands of patients and were as likely to discuss communication as swallowing. They were less reticent about sharing specialist communication expertise with therapists than nurses.

\section{$\underline{\text { SLT Interview }}$}

I don't want to undermine their (nurses) ability, I don't want to step on other people's toes, and whereas maybe I'd feel (...) more comfortable doing that with therapists, say 
“oh honestly I'm happy to help out, call me in", I'll just jump in and see if I can support them, whereas I think I wouldn't with nurses (...) I wouldn't want to stand on their toes and say like "I can support this patient" [Georgia (1yr)]

SLTs were far more likely to spend time with therapists than nurses socially. They usually took lunch at the same time and formed a discernible group even in space that was ostensibly shared. For example, the staff room on Shelley had two circular tables that each comfortably fit four or five people. My fieldnotes record an occasion when one table had ten allied health professionals sitting around it chatting animatedly and the other was occupied by two nurses sitting in silence [FN021015]. As a researcher attempting to achieve acceptance by both SLTs and nurses I was unable to decide where to sit and left the room. SLTs reported occasional participation in nursing social events, but this was uncommon. For example, one of the SLTs identified herself as unusual when giving an example of being the only therapist at the drinks of a particularly popular nurse. The temporal-spatial context thus influenced interaction for both professional and social purposes.

\section{Discussion}

Findings have been presented that demonstrate that the context in which information-sharing occurs influences the nature of patient-related information subsequently shared and affects relationship building. The temporal-spatial context (figure 1) favoured fast, functional exchanges of immediately usable information for keeping patients safe from physical harm. This research has revealed that SLTs perceive that when they attempt to speak to a nurse, this interaction is disturbing to nursing work and so they adopt a strategy to create a brief 'window in time' to convey their information. As such, this study supports the findings by Burm and colleagues that interactions may be more strategic than opportunistic [7]. This appears to be the first study to identify the concept of interruptions as central to how SLTs work with nurses on 
stroke units, and in so doing increases understanding for the complexity of interruptive behaviour [13]. This provides a new perspective to existing research, which rarely focuses on the 'interrupter' [7], more usually directing attention to the impact on nurses as the interrupted party $[15,24]$. The SLTs in this study were so frequently observed waiting for an opportune moment to interrupt or looking for nurses, that attempts to gain their attention could be considered a core component of the SLT role on stroke units.

Symbolic interactionists argue that the perceptions actors (people) hold about the usefulness of things are based on the meaning they ascribe to them, influencing how they act towards them [32]. This makes it a useful lens for understanding interruptive behaviour. People are continuously engaged in goal directed activity and the way they define the current situation (and its usefulness) influences whether or not they will put their own goals aside to attend [48]. Looking, waiting and interrupting placed a burden on SLTs that they appeared more prepared to carry for information they judged to be of immediate use to nursing work. They expected nurses to find swallowing information useful but rarely displayed similar confidence that communication information was of sufficient importance that they could implore nurses to temporarily suspend their busyness to give their attention to it.

Nurses working on stroke wards experience frequent interruptions and high workloads in ways that have similarities with other acute settings $[13,14]$. Nurses base decisions about what to attend to or disregard on perceptions of what they need to know to perform their roles [49]. Interruptions are often qualified in the literature according to necessity. For example, it has been suggested that nurses should act assertively "to avoid unnecessary interruptions" [24:1504]. An interview study with nurses and doctors from emergency departments in Sweden indicated that interruptions could shift from being perceived as disturbing to non-disturbing 
when the information was considered relevant to the task at hand, or when workload was light [13]. SLTs and nurses operate in different temporal-spatial dimensions that make it difficult to find time to talk (see figure 1). Nurses' position at the centre of patient care requires them to make sense of large quantities of incoming information from diverse sources [13] and the SLTs in the current study acted with awareness that they were just one of many professionals approaching them to share their specialist knowledge. They were 'few' and nurses were 'many', impeding SLTs' familiarity with individual nurses. SLTs' responsibility for the same patients from admission to discharge contrasted with changes in nurses from shift to shift. This reduced the opportunities for the repeated discussions about patient management that appear important for developing professional relationships $[3,8,11]$.

Need for information is an important contingency that underpins interprofessional communication [8] and SLTs judged swallowing information to be 'needed information' that they could share quickly and succinctly. Herbert Mead argued that people use 'self-talk' to interpret meaning during interaction, forming a basis for how they decide to act [50]. SLT 'selftalk' was shaped by restrictions in time available for the interaction. It led the SLTs in this study to limit what they shared about communication, based on judgments about what was of sufficient importance to warrant disturbing the flow of nursing work. Geertz suggests that "man is an animal suspended in webs of significance he himself has spun" [36:145]. Acceptance by SLTs of the prominence of swallowing in the acute setting [51-53] could be considered a selfspun web that makes them reticent to challenge the narrowed space for sharing specialist knowledge about communication.

Previous research indicates that SLTs perceive that higher status is associated with their expertise with dysphagia than with communication in the prevailing medical model of acute 
care $[51,52,54]$. To our knowledge, this is the first empirical study to reveal interactional factors that may underpin and sustain the low profile of communication information on stroke units. SLTs oriented to the small windows in time for informal interaction as being spaces primarily for swallowing information. Ineffective sharing of information about communication is likely to have consequences for patients. Studies with people with aphasia report a wide range of negative feelings associated with their experiences of communicating with healthcare providers in hospital, such as frustration, loss, uncertainty, confusion, strangeness, insecurity, exclusion, and fear [55-57]. Existing research indicates that there is a need amongst professionals for enhanced knowledge and skills to improve the communicative experiences of patients [54]. Health care professionals (including nurses) working in inpatient stroke teams indicated the challenges they experienced in communicating with people with aphasia during focus groups [54]. They wanted to give more support to help patients communicate but were unsure how to achieve this in the limited time available. Although SLTs recommended communication support strategies for patients, clinicians did not feel sufficiently equipped to apply them in practice [54].

It has been suggested that interruptions may be better tolerated when relationships are stronger [14]. The SLTs in this study felt more allied with therapists than nurses, having more in common with them from a temporal-spatial perspective [8]. Interaction between SLTs and nurses was more transactional than relational, with nurses more commonly recipients of SLT recommendations than discursive partners. Contrary to previous research about therapist-nurse communication [27], the nurses in this study did not view being given advice as a dissatisfaction, in fact they welcomed clear instruction from SLTs about swallowing when it helped them in tangible ways. Nevertheless, there was a notable contrast with how SLTs viewed the more expansive interaction they experienced with other therapists. Previous research has 
suggested that there are tensions in the therapist-nurse relationship that stem from therapists' undervaluing nursing roles $[10,11]$. However, failure to respect roles only partially explains tensions in interprofessional practice [8]. It has been argued that effective interprofessional communication is underpinned by the contingencies of quality of relationships, need for information, capacity to hear, hold and use information, and opportunity to interact [8]. This study has exposed the mechanics of informal interaction between SLTs and nurses and shows the influence of the temporal-spatial context on these contingencies. This new understanding may help identify ways that alignment could be increased and thereby open up potential for richer information sharing and more effective collaboration around patient care [3].

\section{Strengths, limitations and future directions}

The study has made a significant contribution to the very small body of SLT-directed research that has used ethnographic methodology to understand SLT practice. It appears to be the first ethnography that focuses on information-sharing between SLTs and nurses on stroke units. My familiarity with the language and routines of team-based inpatient care eased the process of understanding what people were talking about and gave me common ground with staff as a fellow health care professional. Being present as a researcher unburdened by professional role increased my scope for openness to the perspectives of both disciplines. However, it is likely that a nurse-researcher would have asked different questions of those in the field and noticed things that I did not. Future studies would benefit from being conducted by SLTs and nurses as co-researchers. Rich description has increased the potential for readers to judge whether the findings transfer to other stroke unit settings. Nevertheless, the findings are situated in a particular time and place. The perspectives of other therapists would have extended understanding for differences between SLT-nurse and SLT-therapist relationships. In addition, 
exploring the patient perspective would have added an important third perspective to the topic of SLT-nurse information-sharing about communication and swallowing needs.

It is recommended that pre-registration training for SLTs better prepares them for the context in which they will need to share information with other health care professionals, particularly nurses. Specifically, that interactions are often disturbing to nursing work and that consideration needs to be given to making it very clear how information is relevant and can be put to use. Appreciation of the temporal-spatial context has potential to support stroke teams to explore how relationships can be fostered with all in the team, not just those with whom they are more naturally aligned. Further research is suggested to explore how temporal-spatial alignment could be enhanced as a way of increasing sharing of knowledge held by both disciplines about patients' communication. For example, the proximal/distal difference (figure 1) could potentially be reduced if SLTs and nurses worked together on tasks such as personal care and used these as opportunities to address communication goals in meaningful ways that fit with nurse capacity. Likewise, the intermittent/constant and few/many differences might be mitigated by increasing continuity of individual nurses for care for individual patients across the admission-discharge trajectory. Stroke rehabilitation nursing staff have called for this as a means to increase knowledge of, and relationships with, patients [58]. Greater continuity would also increase opportunities for meaningful interprofessional discussion [11].

\section{Conclusion}

The SLT-nurse partnership is pivotal when considering how to make information about communication and swallowing sufficiently relevant and useful to nursing work for it to be incorporated into nursing care. Swallowing information was a better fit with the temporalspatial context in which information was shared. SLT need to disturb nurses' flow of work led 
them to self-limit sharing of information about communication. Better sharing of information has the potential to improve patients' experience of communication in hospital.

\section{Disclosure statement}

No potential conflict of interest was reported by the authors.

\section{References}

[1] Langhorne P, Ramachandra S. Organised inpatient (stroke unit) care for stroke: network meta-analysis. Cochrane Database Syst Rev 2020;4: CD000197.

[2] Rudd AG, Bowen A, Young G, James MA (2016). National Clinical Guideline for Stroke: $5^{\text {th }}$ edition. Clinical Medicine. Available from https://www.rcplondon.ac.uk/guidelines-policy/stroke-guidelines

[3] Clarke DJ. Achieving teamwork in stroke units: The contribution of opportunistic dialogue. J Interprof Care. 2010; 24(3):285-297.

[4] Lewin S, Reeves S. Enacting 'team' and 'teamwork': using Goffman's theory of impression management to illuminate interprofessional practice on hospital wards. Soc Sci Med. 2011;72(10): 1595-1602.

[5] Tyson SF, Burton L, McGovern A. Multi-disciplinary team meetings in stroke rehabilitation: an observation study and conceptual framework. Clin Rehabil. 2014;28:1237-1247.

[6] Walton V, Hogden A, Long JC et al. Clinicians perceptions of rounding processes and effectiveness of clinical communication. J Eval Clin Pract. 2019:1-11.

[7] Burm S, Boese K, Faden L et al. Recognising the importance of informal communication events in improving collaborative care. BMJ Qual Saf.2019;28:289-295.

[8] Barnard R, Jones J, Cruice M. Communication between therapists and nurses working in inpatient interprofessional teams: Systematic review and meta-ethnography. Disabil Rehabil. 2020;42(10):1339-1349.

[9] Clarke DJ. Nursing practice in stroke rehabilitation: systematic review and metaethnography. J Clin Nurs. 2014;23:1201-1226. 
[10] Pryor J. A nursing perspective on the relationship between nursing and allied health professionals in inpatient rehabilitation. Disabil Rehabil. 2008;30(4):314-322.

[11] Digby R, Bolster D, Perter A et al. The perspective of allied health staff on the role of nurses in subacute care. J Clin Nurs. 2018;27:4089-4099.

[12] Miller K, Reeves S, Zwarenstein M et al. Nursing emotion work and interprofessional collaboration in general internal medicine wards: a qualitative study. J Adv Nurs. 2008;64:332-343.

[13] Berg LM, Kallberg A, Ehrenberg A et al. Factors influencing clinicians' perceptions of interruptions as disturbing or non-disturbing: A qualitative study. Int Emerg Nurs. 2016;27:11-16.

[14] Hopkinson SG, Wiegand DL. The culture contributing to interruptions in the nursing work environment: An ethnography, J Clin Nurs. 2017;26:5093-5102.

[15] McGillis Hall L, Ferguson-Pare M, Peter E, et al. Going blank: factors contributing to interruptions to nurses' work and related outcomes. J Nurs Manag. 2010;18:10401047.

[16] Stroke Foundation [internet]. Clinical Guidelines for Stroke Management. Australia: Accessed $17^{\text {th }}$ June, 2020. Available from https://informme.org.au/en/Guidelines/Clinical-Guidelines-for-Stroke-Management

[17] Mitchell C, Gittins M, Tyson et al. Prevalence of aphasia and dysarthria among inpatient stroke survivors: describing the population, therapy provision and outcomes on discharge. Aphasiology. 2020. https://doi.org/10.1080/02687038.2020.1759772

[18] Martino R, Foley N, Bhogal S et al. Dysphagia after stroke: Incidence, diagnosis, and pulmonary complications. Stroke. 2005;36(12):2756-2763.

[19] Pound C, Jensen LR. Humanising communication between nursing staff and patients with aphasia: Potential contributions of the humanisation values framework. Aphasiology. 2018;32(10):1209-1233.

[20] Hines S, Kynoch K, Munday J. Nursing interventions for identifying and managing acute dysphagia are effective for improving patient outcomes: A systematic review update. $\mathbf{J}$ Neurosci Nurs. 2016;48(4):214-222.

[21] Kenny T, Barr C, Laver K. Management of fever, hyperglycaemia, and dysphagia in an acute stroke unit. Rehabil Nurs. 2016;41:313-319.

[22] O'Keefe ST. Use of modified diets to prevent aspiration in oropharyngeal dysphagia: is current practice justified? BMC Geriatr. 2018;18:167. 
[23] Peter E \& Liaschenko J. Perils of proximity: A spatiotemporal analysis of moral distress and moral ambiguity. Nurs Inq. 2004;11(4):218-225.

[24] Lausten S, Brahe L. Coping with interruptions in clinical nursing - a qualitative study, J Clin Nurs. 2018;27:1497-1506.

[25] McKnight LK, Stetson PD, Bakken S et al. Perceived information needs and communication difficulties of inpatient physicians and nurses. J Am Med Inform Assoc. 2001;9:64-69.

[26] Long AF, Kneafsey R, Ryan J et al. The role of the nurse within the multi-professional rehabilitation team. J Adv Nurs. 2002;37(1):70-78.

[27] Miller K, Kontos PC. The intraprofessional and interprofessional relations of neurorehabilitation nurses: A negotiated order perspective. J Adv Nurs. 2013;69 (8):1797-807.

[28] Seneviratne CC, Mather CM, Then KL. Understanding nursing on an acute stroke unit: Perceptions of space, time and interprofessional practice. J Adv Nurs. 2009;65(9):1872-1881.

[29] Hammersley M, Atkinson P. Ethnography: Principles in Practice. Oxon; New York: Routledge. 2019.

[30] Rock P, (2001). Symbolic interactionism and ethnography. In P Atkinson, A Coffey, S Delamont, J Lofland J, L Lofland (ed), Handbook of Ethnography. London; Thousand Oaks; New Delhi: Sage Publications. 2001.

[31] Hammersley, M. What is ethnography? Can it survive? Should it? Ethnog Education. 2018;13(1):1-17.

[32] Blumer H. Symbolic Interactionism. Berkeley (CA): University of California Press; 1969.

[33] Clifford J, Marcus G. Writing Culture: The Poetics and Politics of Ethnography. Berkeley (CA): University of California Press; 1986.

[34] Quirk A, Lelliott P, Seale C. The permeable institution: An ethnographic study of three acute psychiatric wards in London. Soc Sci Med. 2006;63:2105-2117.

[35] Rapley T. Interviews. In: C. Seale, editor. Qualitative research practice. Thousand Oaks (CA): Sage; 2004.

[36] Geertz C. The Interpretation of Cultures. New York (NY): Basic Books; 1973.

[37] Glaser BG, Strauss AL. The discovery of grounded theory: Strategies for qualitative research. Chicago (IL): Aldine; 1967.

[38] NVIVO 11. QSR International Pty Ltd: 2015. 
[39] Charmaz, K, Mitchell, RG. Grounded theory in ethnography. In P Atkinson, A Coffey, S Delamont, J Lofland J, L Lofland (ed), Handbook of Ethnography. London; Thousand Oaks; New Delhi: Sage Publications. 2001.

[40] Thorne S. Interpretative Description. London (UK): Routledge; 2016.

[41] Guba, E., Lincoln, Y. Naturalistic Inquiry. Newbury Park (CA): Sage; 1985.

[42] Sandelowski M. Rigor or rigor mortis: The problem of rigor in qualitative research revisited. Adv Nurs Sci. 1993;16(2):1-8.

[43] Crotty M. The foundations of social research. London (UK): Sage; 1998.

[44] Bloor, M. The ethnography of health and medicine. In P Atkinson, A Coffey, S Delamont, J Lofland J, L Lofland (ed), Handbook of Ethnography. London; Thousand Oaks; New Delhi: Sage Publications. 2001.

[45] Hall PM. Interactionism, social organization, and social processes: looking back and moving ahead. Symbolic Interactionism. 1993;26(1):33-55.

[46] Barnard R. Speech and language therapist and nurse information sharing: An ethnographic study on stroke units [dissertation]. London (UK): City, University of London; 2020. Available from https://openaccess.city.ac.uk/id/eprint/24392/

[47] Eldh, AC, Arestedt, L, Bertero, C. Quotations in qualitative studies: Reflections on constituents, custom and purpose. Int J Qual Methods. 2020;19.

[48] Charon J. Symbolic Interactionism: An introduction, An interpretation, An integration, $10^{\text {th }}$ edition. Boston (MA): Prentice Hall; 2010.

[49] Allen D. Re-conceptualising holism in the contemporary nursing mandate: from individual to organisational relationships. Sociol Sci Med. 2014; 119: 131-138.

[50] Mead G. Mind, Self and Society. Chicago (IL): University of Chicago Press. 1934.

[51] Foster A, Worrall L, Rose M et al. 'That doesn't translate': The role of evidence-based practice in disempowering speech pathologists in acute aphasia management. Int $\mathbf{J}$ Lang Comm Dis. 2015;50(4):547-563.

[52] Foster A, O'Halloran R, Rose ML et al. "Communication is taking a back seat": speech pathologists' perceptions of aphasia management in acute hospital settings. Aphasiology. 2016;30(5):585-608.

[53] Rose M, Ferguson A, Power E et al. Aphasia rehabilitation in Australia: Current practices, challenges and future directions. Int J Speech-Lang Pa. 2014;16(2):169-180.

[54] Carragher M, Steel G, O’Halloran R et al. Aphasia disrupts usual care: The stroke team's perceptions of delivering healthcare to patients with aphasia. Disabil Rehabil.

2020;11:1-12. 
[55] Clancy L, Povey R, Rodham K. "Living in a foreign country": experiences of staffpatient communication in inpatient stroke settings for people with post-stroke aphasia and those supporting them. Disabil Rehabil. 2018; 27(1):1-11.

[56] Johannsen MB, Carlsson M, Sonnander, K. Communication difficulties and the use of communication strategies: from the perspective of individuals with aphasia. Int J Lang Comm Dis. 2012;47(2):144-155.

[57] Loft MI, Martinsen B, Esbensen BA et al. Call for human contact and support: an interview study exploring patients' experiences with inpatient stroke rehabilitation and their perception of nurses' and nurse assistants' roles. Disabil Rehabil. 2019;41(4):396-404.

[58] Loft MI, Poulsen I, Esbensen BA et al. Nurses' and nurse assistants' beliefs, attitudes and actions related to role and function in an inpatient stroke rehabilitation unit - a qualitative study. J Clin Nurs. 2017;26:4905-4914. 
Table 1 Fieldwork summary

\begin{tabular}{|l|l|l|l|l|l|}
\hline $\begin{array}{l}\text { Name of } \\
\text { ward }\end{array}$ & Trust & $\begin{array}{l}\text { Type of } \\
\text { ward }\end{array}$ & $\begin{array}{l}\text { Stroke } \\
\text { beds }\end{array}$ & $\begin{array}{l}\text { Duration of } \\
\text { fieldwork }\end{array}$ & $\begin{array}{l}\text { Fieldwork } \\
\text { hours }\end{array}$ \\
\hline Keats & One & Hyper-acute & 18 & 12 weeks & 110 \\
\hline Shelley & One & Acute & 17 & 16 weeks & 124.5 \\
\hline Brooke & Two & Acute & 24 & 12 weeks & 122.5 \\
\hline
\end{tabular}

Table 2: Participant Information

\begin{tabular}{|c|c|c|c|}
\hline \multicolumn{2}{|c|}{ Biographical information } & SLT & Nursing \\
\hline \multicolumn{2}{|c|}{ Participants } & 16 & 57 \\
\hline \multicolumn{2}{|l|}{ Gender } & Female (16) & Female (41) Male (16) \\
\hline $\begin{array}{l}\text { Nature of } \\
\text { participation }\end{array}$ & $\begin{array}{l}\text { Interviewed } \\
\text { Observed }\end{array}$ & $\begin{array}{l}15 \text { (14 SLT, } 1 \text { SLTA) } \\
16 \text { (15 SLT, } 1 \text { SLTA) }\end{array}$ & $\begin{array}{l}28 \text { (24 Nurse, } 4 \text { NA) } \\
57 \text { (50 Nurse, } 7 \text { NA) }\end{array}$ \\
\hline NHS pay bands & $\begin{array}{l}\text { Band 8b } \\
\text { Band } 7 \\
\text { Band } 6 \\
\text { Band 5 } \\
\text { Band 2-3 }\end{array}$ & $\begin{array}{l}1 \\
8 \\
4 \\
2 \\
1\end{array}$ & $\begin{array}{l}0 \\
5 \\
10 \\
35 \\
7\end{array}$ \\
\hline $\begin{array}{l}\text { Years of } \\
\text { experience: } \\
\text { Collected for } \\
\text { interview } \\
\text { participants only }\end{array}$ & $\begin{array}{l}\text { Range } \\
\text { Mean } \\
\text { Median }\end{array}$ & $\begin{array}{l}1.5-27 \text { years } \\
7.7 \text { years } \\
5 \text { years }\end{array}$ & $\begin{array}{l}4 \text { months }-40 \text { years } \\
8.6 \text { years } \\
5 \text { years }\end{array}$ \\
\hline
\end{tabular}

Figure 1. The temporal-spatial context of information-sharing between SLTs and nurses

\begin{tabular}{|c|c|c|}
\hline $\begin{array}{l}\text { SLT } \\
\text { INTERMITTENT } \\
\text { SLTs were present during } \\
\text { 'office hours' } \\
\text { FEW } \\
\text { Usually only 1-2 SLTs } \\
\text { were responsible for } \\
\text { specific patients from } \\
\text { admission to discharge } \\
\text { DISTAL } \\
\text { SLTs allocated to patients } \\
\text { came and went from } \\
\text { bedside }\end{array}$ & ADMISSION & $\begin{array}{l}\text { NURSING } \\
\text { CONSTANT } \\
\text { Nursing staff were present } \\
\text { every day and night } \\
\text { MANY } \\
\text { Responsibility of individual } \\
\text { nurses for specific patients } \\
\text { transferred with shift } \\
\text { changes } \\
\text { PROXIMAL } \\
\text { Nursing staff allocated to } \\
\text { patients remained close to } \\
\text { bedside }\end{array}$ \\
\hline
\end{tabular}

